\title{
Characteristics of Material AND Fabrication FOR CONCRETE STRUCTURES IN INDONESIA
}

\section{Ashar Saputra ${ }^{1,2}$, Ekasit Limsuwan ${ }^{2 *}$, and Tamon Ueda ${ }^{3}$}

1 Ph.D. student sandwich program, Chulalongkorn University, Thailand

and Hokkaido University, Japan

2 Department of Civil Engineering, Faculty of Engineering,

Chulalongkorn University, Bangkok 10330, Thailand

${ }^{3}$ Division of Built Environment, Hokkaido University, Japan

(Kita 13, Nishi 8, Kita-ku, Sapporo-shi Hokkaido 060-0813, Japan)

E-mail: ashar@tsipil.ugm.ac.id,fceels@eng.chula.ac.th*, and

ueda@eng.hokudai.ac.jp

\section{ABSTRACT}

As part of resistance of a structure, statistical characteristics of material and member fabrication play important aspect on the reliability analysis of all the limit states. This paper shows the statistical characteristics of material including concrete compressive strength, yield stress and diameter of reinforcing bars, which represent the condition of material production in Indonesia. The precision of fabrication of member displaying the level of workmanship, equipment appropriateness and quality control system is also presented. Data was collected from five construction sites include apartments, office, hospital and public facility located in Jakarta and Yogyakarta. The statistical parameters of concrete compressive strength and fabrication of members are partially compared with the similar information from Japan and USA. The statistical characteristics for material and fabrication from Indonesia show narrow deviations in comparison with those from Japan and USA for the case of normal concrete and conventional method of construction.

\section{KEYWORDS}

statistical characteristics, reinforced concrete, material strength, fabrication 


\section{Introduction}

Construction practices and industry have been growing fast with support by the accumulated knowledge and progress of technology. Both developed and developing countries have been taking advantages of the progress. However, the quality of construction could be diverse due to the difference in level of technology and economy among different countries. The common problem in the case of developing countries, such as Indonesia, exists in workmanship and construction equipment. Material productions also need to be examined to get the complete figure of performance of product from construction industry.

This paper presents the statistical characteristics of material and fabrication of structural member for reinforced concrete ordinary buildings in Indonesia. The statistical data were taken from five construction sites with contract of different construction companies in 2006 to 2008. The projects are apartment buildings for economically middle-upper and middle-lower classes, a governmental office building, a hospital, and a facility for public. All those construction sites were situated in Jakarta and Yogyakarta. The concrete and reinforcing steel of the construction sites came from several production batches and companies. The data collection was limited to normal concrete and excludes pre-stressed concrete structure. The site were chosen since they are representing the common in term of project conditions and building complexity in Indonesia. In order to obtain complete figure, data of concrete compressive strength also collected from two different concrete companies to investigate the effect of batching plant to the consistency of productions.

The statistical characteristics presented in this paper will play important role in the reliability analysis of certain limit states of reinforced concrete structures. Those also represent skill level of worker and technology level of the construction industry. The analyzed data then partially compared with the similar information from Japan and USA to understand the diverse between developed and developing countries.

\section{Concrete Compressive Strength}

The test data for ordinary concrete were obtained from different construction projects in Indonesia. The data were originally recorded for quality control at sites. For each project, the data were taken from several batches of ready-mixed concrete. Due to some reasons, for contractors with certain grade commonly use ready-mixed concrete from several companies to supply their construction sites.

Additional data were also taken from two different ready-mixed concrete companies to investigate the difference in statistical characteristics of concrete strength between data from more than one ready-mixed factory and data from one factory. The data were originally recorded for the purpose of internal company quality control and report to the owner of the building which is under construction.

All the data of concrete compressive strength were taken based on the Indonesian Concrete Code in which samples of concrete cylinders having diameter of $150 \mathrm{~mm}$ and $300 \mathrm{~mm}$ height have to be taken from each $120 \mathrm{~m}^{3}$ of concrete production or volume of concrete equal to that to cast $500 \mathrm{~m}^{2}$ of floor.

The statistical parameters of concrete strength $f_{c}^{\prime}$ were calculated and presented together with the cumulative distribution function (CDF). The shape of CDF representing test data can be used for interpretation of the type of distribution. The straight line on normal probability scale represents a normal CDF. The slope of CDF can be used to determine the standard deviation.

The CDF curves of $f_{c}^{\prime}$ for all investigated concrete strength taken from the different construction sites are shown in Figure 1 while the statistical parameters (mean values, bias factor -ratio of mean to nominal value- $\lambda$, and coefficient of variation $V$ are listed together with nominal strength and number of sample in Table 1. The different concrete grades were used for the different sites. Each CDF curve represents data taken from one construction site. The ready-mixed concrete for each site was provided by more than one company.

The CDF curves of different concrete compressive strengths specifically taken from two different ready-mixed concrete factories of two different companies in Indonesia are presented in Figure 2(a) and Figure 2(b), while their statistical parameters are presented in Table 2. 
It can be seen In Figure $2 \mathrm{a}$ and Table 2 the concrete grade of $37 \mathrm{MPa}$ which is not regular class for many standards. The data of concrete grade $37 \mathrm{MPa}$ were also made of standard cylinder concrete specimens. In the projects, sometimes the owner asked the supplyer to improve the concrete s due to some adjustment needed during construction.

Figure 1 CDF for compressive strength of ordinary ready-mixed concrete from several construction projects in Indonesia.
Table 1

Statistical parameters for compressive strength of ready-mixed concrete from several construction projects in Indonesia.

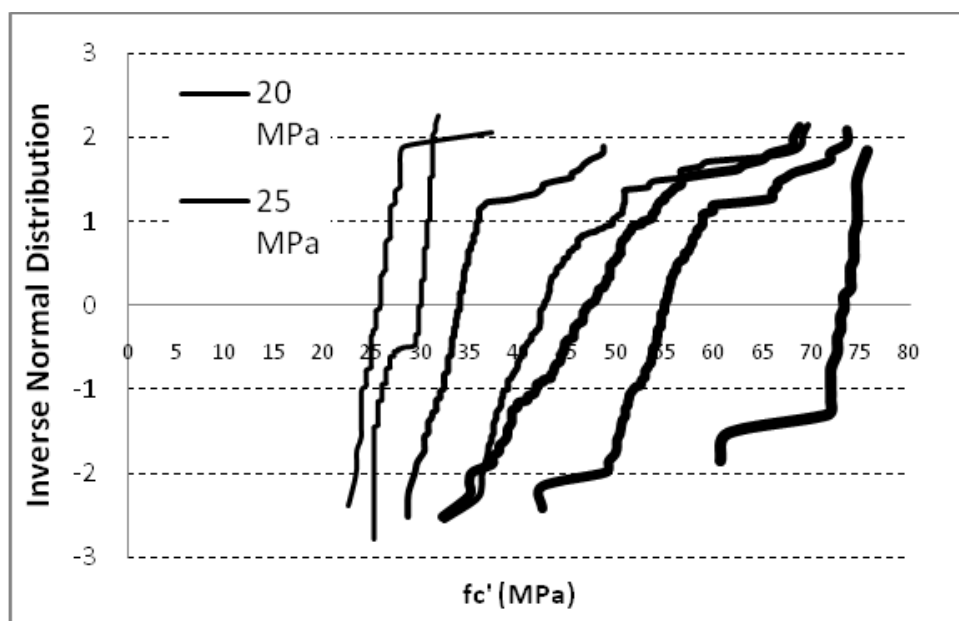

\begin{tabular}{|c|c|c|c|c|c|}
\hline No. & $\begin{array}{c}\text { Class } \\
\mathbf{M P a}\end{array}$ & $\begin{array}{c}\text { Number } \\
\boldsymbol{n}\end{array}$ & $\begin{array}{c}\text { Mean } \\
\mathbf{M P a}\end{array}$ & $\begin{array}{c}\text { Coef. Of Variation } \\
\boldsymbol{V}\end{array}$ & $\begin{array}{c}\text { Bias factor } \\
\boldsymbol{\lambda}\end{array}$ \\
\hline 1. & 20 & 125 & 25.628 & 0.077 & 1.281 \\
\hline 2. & 25 & 391 & 28.204 & 0.166 & 1.128 \\
\hline 3. & 30 & 175 & 34.381 & 0.101 & 1.146 \\
\hline 4. & 35 & 194 & 43.788 & 0.141 & 1.251 \\
\hline 5. & 40 & 178 & 47.499 & 0.131 & 1.187 \\
\hline 6. & 50 & 136 & 55.931 & 0.093 & 1.118 \\
\hline 7. & 55 & 30 & 72.602 & 0.046 & 1.320 \\
\hline
\end{tabular}

For comparison, the similar data from Japan have been analyzed and presented. Those data are two different sets, which were chosen for the comparison of two different sets of the Indonesian data respectively. The first was taken from database collected by Public Work Research Institute (PWRI) of Japan during 1992-1994 and limited on classes of $21 \mathrm{MPa}$ and $24 \mathrm{MPa}$ [1]. Samples were taken and tested by government officer at many construction sites of bridges piers, culverts and slabs. The data were originally taken for the purpose of surveying quality of concrete at actual sites. Data from PWRI were chosen based on the fact that those project use concrete from several ready-mixed concrete producers.

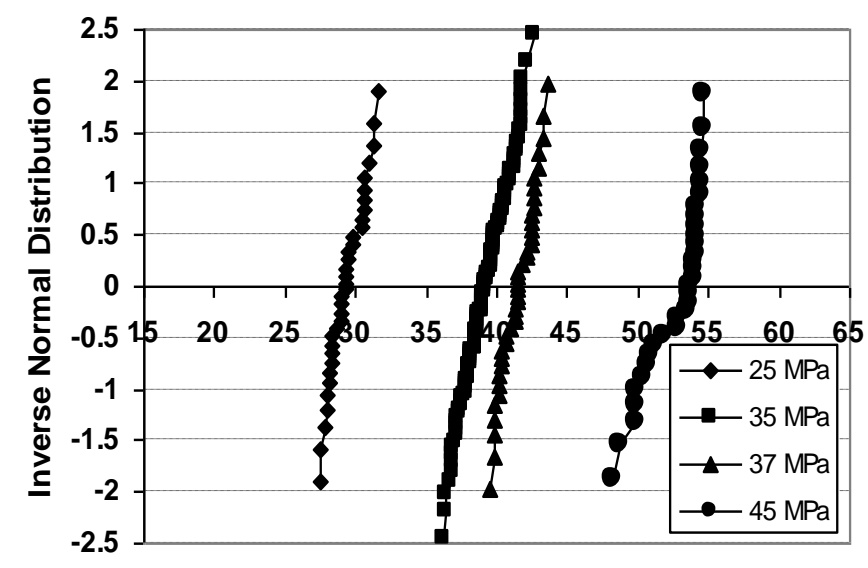

Company A
Figure 2(a)

CDF of compressive strength of ordinary ready-mixed concrete from two different concrete companies in Indonesia (Company A). $f c^{\prime}(\mathrm{MPa})$ 


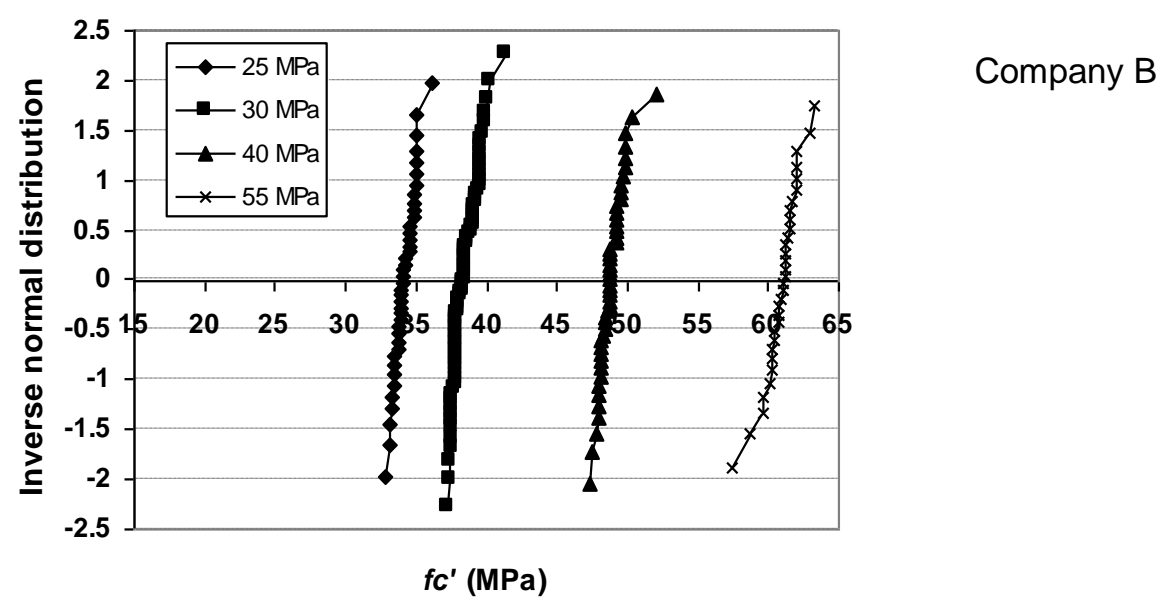

Figure 2(b)

CDF of compressive strength of ordinary ready-mixed concrete from two different concrete companies in Indonesia (Company B).

\begin{tabular}{|c|c|c|c|c|c|c|}
\hline Company & No. & $\begin{array}{c}\text { Class } \\
\mathbf{M P a}\end{array}$ & $\begin{array}{c}\text { Number } \\
\boldsymbol{n}\end{array}$ & $\begin{array}{c}\text { Mean } \\
\mathbf{M P a}\end{array}$ & $\begin{array}{c}\text { Coef. Of Variation } \\
\boldsymbol{V}\end{array}$ & $\begin{array}{c}\text { Bias factor } \\
\boldsymbol{\lambda}\end{array}$ \\
\hline \multirow{4}{*}{$\mathrm{A}$} & 1. & 25 & 135 & 29.330 & 0.040 & 1.173 \\
\cline { 2 - 7 } & 2. & 35 & 136 & 39.273 & 0.037 & 1.122 \\
\cline { 2 - 7 } & 3. & 37 & 140 & 41.252 & 0.028 & 1.122 \\
\cline { 2 - 7 } & 4. & 45 & 131 & 52.762 & 0.037 & 1.171 \\
\hline \multirow{4}{*}{ B } & 1. & 25 & 140 & 34.200 & 0.021 & 1.368 \\
\cline { 2 - 7 } & 2. & 30 & 186 & 38.516 & 0.021 & 1.284 \\
\cline { 2 - 7 } & 3. & 40 & 147 & 48.808 & 0.017 & 1.220 \\
\cline { 2 - 7 } & 4. & 55 & 132 & 60.947 & 0.018 & 1.108 \\
\hline
\end{tabular}

Table 2

Statistical parameter for ready-mixed concrete from two different companies in Indonesia.

The second set of data came from two ready-mixed concrete companies in Hokkaido and Fukuoka, which are northern and southern parts of Japan. This kind of data was taken to control the concrete production quality in order to maintain the certification of ready-mixed concrete company. Sample tests were made one for every $150 \mathrm{~m}^{3}$ of concrete production no matter purposes for the concrete will be.

The CDF of compressive strength and their statistical parameters from the PWRI's data are shown in Figure 3 and Figure 4. The CDF of ready-mixed normal concrete for concrete strength taken from two companies in Japan are shown in Figure 5(a) and Figure 5(b), while the statistical parameters are listed in Table 3.

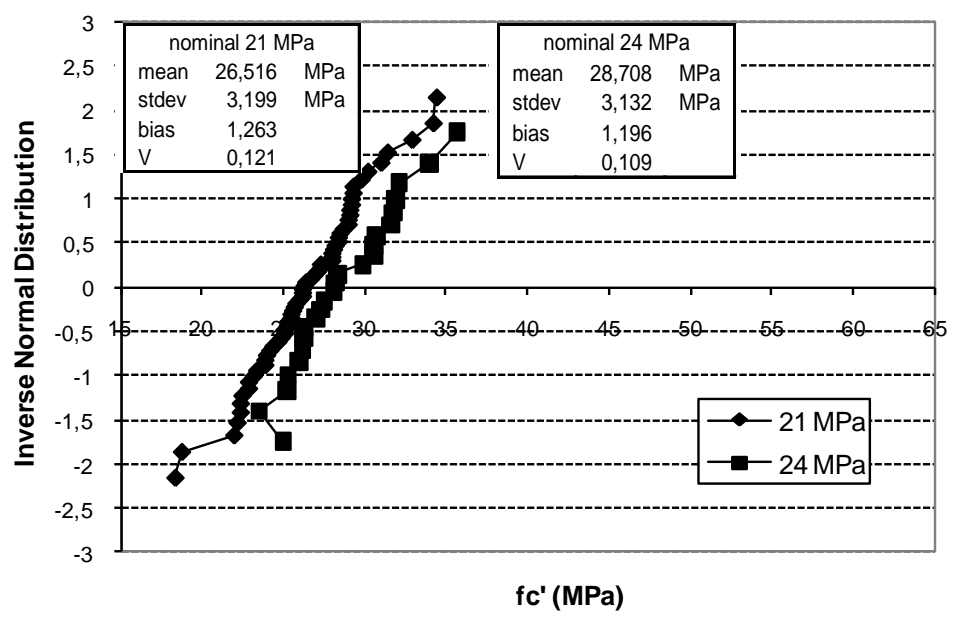

Figure 3

CDF of ordinary readymixed concrete for classes $21 \mathrm{MPa}$ and 24 MPa in 1992 in Japan [1]. 
Other similar information also can be found for the case of USA [2] that presents the result of research to provide new statistical parameter for reinforced concrete material. The material strengths were based on test results provided by North American industry, and selection of sources was coordinated by organizations including the Concrete Reinforcing Steel Institute, the National Ready Mixed Concrete Association, the Portland Cement Association, and the Precast/Prestressed Concrete Institute. The statistical parameters for concrete compressive strength for the case of USA are presented on Table 4.

Figure 4

CDF of ordinary readymix concrete for class 21 $\mathrm{MPa}$ in 1992 to 1994 in Japan [1].

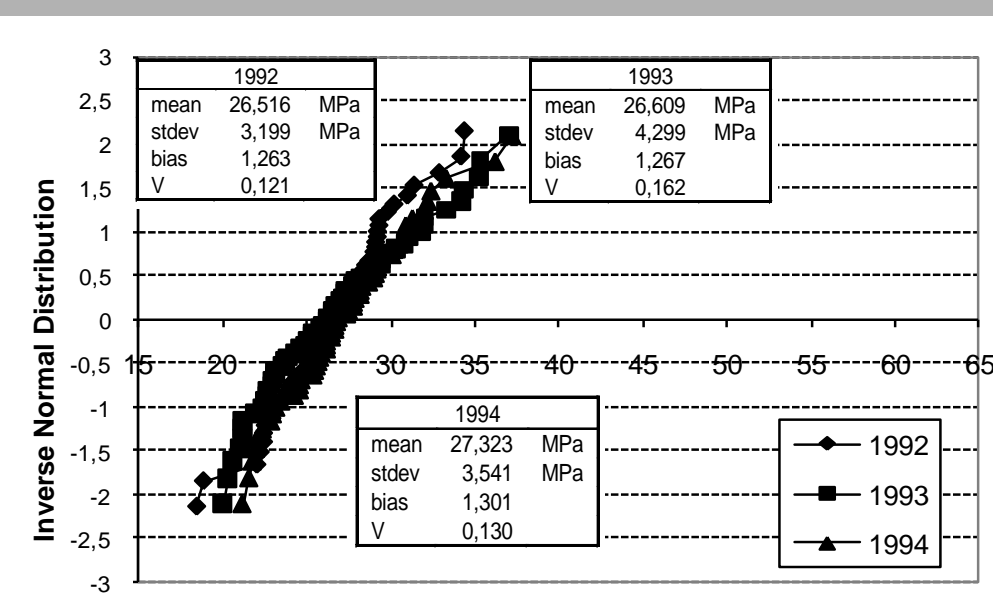

fc' (MPa)
Figure 5(a)

CDF of compressive strength of ordinary ready-mixed concrete from two different companies in Japan (Hokkaido area) [1].

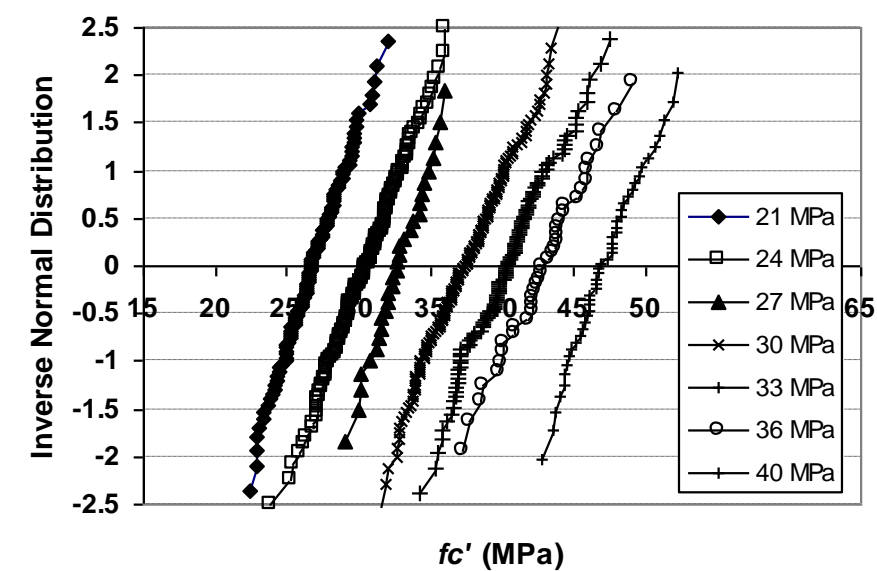

Hokkaido area

\section{Figure 5(b)}

CDF of compressive strength of ordinary ready-mixed concrete from two different companies in Japan (Fukuoka area) [1].

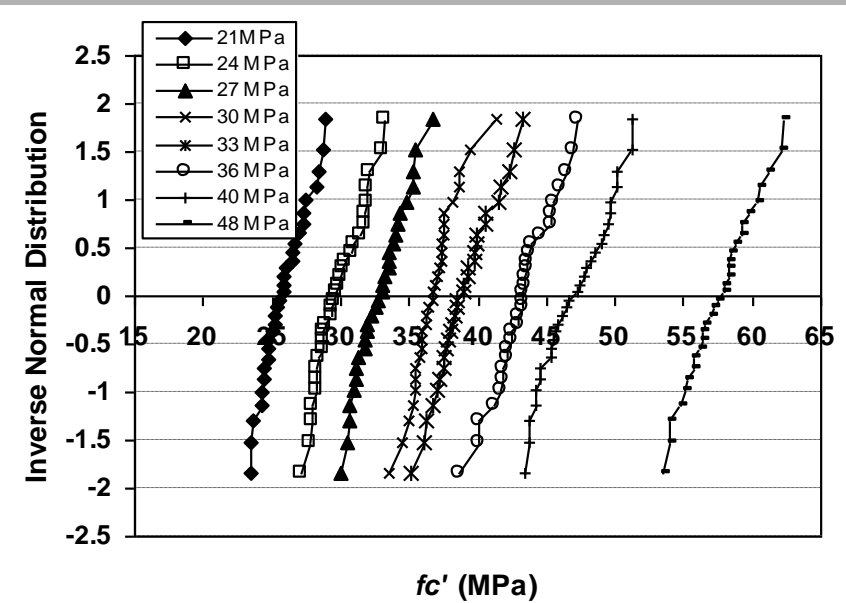




\begin{tabular}{|c|c|c|c|c|c|c|}
\hline Company & No. & $\begin{array}{c}\text { Class } \\
\mathbf{M P a}\end{array}$ & $\begin{array}{c}\text { Number } \\
\boldsymbol{n}\end{array}$ & $\begin{array}{c}\text { Mean } \\
\mathbf{M P a}\end{array}$ & $\begin{array}{c}\text { Coef. of Variation } \\
\boldsymbol{V}\end{array}$ & $\begin{array}{c}\text { Bias factor } \\
\boldsymbol{\lambda}\end{array}$ \\
\hline \multirow{5}{*}{ Hokkaido } & 1 & 21 & 30 & 25.840 & 0.060 & 1.230 \\
\cline { 2 - 7 } & 2 & 24 & 30 & 29.880 & 0.056 & 1.245 \\
\cline { 2 - 7 } & 3 & 27 & 30 & 32.840 & 0.052 & 1.216 \\
\cline { 2 - 7 } & 4 & 30 & 30 & 36.757 & 0.042 & 1.225 \\
\cline { 2 - 7 } & 5 & 33 & 30 & 38.970 & 0.051 & 1.181 \\
\cline { 2 - 7 } & 6 & 36 & 30 & 43.310 & 0.047 & 1.203 \\
\cline { 2 - 7 } & 7 & 40 & 30 & 47.087 & 0.050 & 1.177 \\
\cline { 2 - 7 } & 8 & 48 & 30 & 57.593 & 0.041 & 1.200 \\
\hline \multirow{5}{*}{ Fukuoka } & 1 & 21 & 111 & 26.805 & 0.077 & 1.276 \\
\cline { 2 - 7 } & 2 & 24 & 159 & 30.548 & 0.077 & 1.273 \\
\cline { 2 - 7 } & 3 & 27 & 30 & 32.747 & 0.056 & 1.213 \\
\cline { 2 - 7 } & 4 & 30 & 176 & 37.410 & 0.072 & 1.247 \\
\cline { 2 - 7 } & 5 & 33 & 115 & 40.356 & 0.068 & 1.222 \\
\cline { 2 - 7 } & 6 & 36 & 37 & 42.935 & 0.067 & 1.193 \\
\cline { 2 - 7 } & 7 & 40 & 51 & 47.163 & 0.049 & 1.179 \\
\hline
\end{tabular}

Table 3

Statistical parameter for compressive strength of ready-mixed concrete from companies in Hokkaido and Fukuoka [1].

\begin{tabular}{|c|c|c|c|c|c|}
\hline No. & $\begin{array}{c}\text { Class } \\
\mathbf{M P a} \\
(\mathbf{p s i})\end{array}$ & $\begin{array}{c}\text { Number } \\
\boldsymbol{n}\end{array}$ & $\begin{array}{c}\text { Mean } \\
\mathbf{M P a}\end{array}$ & $\begin{array}{c}\text { Coef. Of Variation } \\
\boldsymbol{V}\end{array}$ & $\begin{array}{c}\text { Bias factor } \\
\lambda\end{array}$ \\
\hline 1. & $\begin{array}{l}20.670 \\
(3000)\end{array}$ & 88 & 27.970 & 0.102 & 1.350 \\
\hline 2. & $\begin{array}{l}24.115 \\
(3500)\end{array}$ & 25 & 29.214 & 0.079 & 1.210 \\
\hline 3. & $\begin{array}{l}27.560 \\
(4000)\end{array}$ & 116 & 34.310 & 0.145 & 1.240 \\
\hline 4. & $\begin{array}{l}31.005 \\
(4500)\end{array}$ & 28 & 35.310 & 0.042 & 1.140 \\
\hline 5. & $\begin{array}{l}34.450 \\
(5000)\end{array}$ & 30 & 39.480 & 0.058 & 1.120 \\
\hline 6. & $\begin{array}{l}41.340 \\
(6000)\end{array}$ & 30 & 46.163 & 0.042 & \\
\hline
\end{tabular}

Table 4

Statistical parameters for ordinary ready-mix concrete in USA [2].

The CDF's and statistical parameters for concrete strength taken from different construction sites in Indonesia show that there are no certain relation between the concrete class and the variations of concrete strength. The coefficients of variation $V$ varies from the values of 0.046 for $55 \mathrm{MPa}$ to 0.166 for $25 \mathrm{MPa}$; while the bias factors, $\lambda$, vary between the value of 1.118 for $50 \mathrm{MPa}$ and 1.320 for $55 \mathrm{MPa}$ (see Table 1). CDF and statistical parameters of concrete compressive strength taken from two ready-mixed concrete companies show better consistency than those for the different construction sites, by showing lower standard deviations and smaller coefficient of variations (see Table 2). However, the higher grade concrete does not show the better consistency, which is different from the case of the data taken from the different construction sites (see Table 1). The data from the different readymixed concrete companies show different statistical characteristics. The concrete produced by Company "A" shows better quality consistency than Company "B". The concrete by Company " $A$ " shows higher mean compressive strength than that by Company "B". Because of difference in the statistical characteristics among different ready-mixed concrete companies, the data taken from various construction sites, where the concrete was provided by more than one company, show greater coefficients of variation.

As shown in Figure 3, the CDF and statistical parameters of concrete for classes of $21 \mathrm{MPa}$ and $24 \mathrm{MPa}$, which were taken from various construction sites in Japan, are close to those for similar grades taken from various construction sites in Indonesia, especially for the values 
of $V$ and $\lambda$. This fact shows that the statistical characteristics of compressive strength of ready-mixed concrete produced by various companies are similar in Indonesia and Japan. It should be noted that the CDF and statistical parameters in 1992, 1993 and 1994 are similar to each other (see Figure 4).

As shown in Table 3, the data of compressive strength of ready-mixed concrete produced by the company in Hokkaido show the coefficients of variation between 0.060 for grade of 21 $\mathrm{MPa}$ and 0.041 for grade of $48 \mathrm{MPa}$. The coefficient of variation for the data from the company in Fukuoka ranges from 0.077 for grade of $21 \mathrm{MPa}$ and $24 \mathrm{MPa}$ to 0.049 for grade of $40 \mathrm{MPa}$. The ready-mixed concrete in Hokkaido gives better consistency in quality. It is interesting to say that those values of the coefficient of variation are bigger than the corresponding values in Indonesia, which are between 0.017 and 0.040 (see Table 2).

Information from USA listed in Table 4 shown that the $V$ values are between 0.145 and 0.042 and this condition is similar to those the values of $V$ of concrete compressive strength from Indonesia and Japan.. On the values of bias factor $\lambda$, data from USA are between 1.350 and 1.120 and these facts is also similar with those values from different sites in Indonesia and from particular companies in Japan and Indonesia.

The statistical characteristics of concrete compressive strength in Indonesia, Japan, and USA are similar. The statistical characteristics of compressive strength of ready-mixed concrete produced by a single company in both Indonesia and Japan show lower coefficient of variations than those of the concrete produced by several companies. This fact is quite reasonable, considering the situation, which was found in this study, that mean value and standard deviation of compressive strength for the same grade are likely to be different among different ready-mixed concrete companies (or factories).

Overall comparison between the Indonesian, Japanese, and USA data clearly implies that the quality control of ready-mixed concrete in Indonesia, which is a developing country, is quite comparable to that in Japan or in USA. This finding is understandable since practically the same level of technology for producing normal concrete in major ready-mixed concrete factory is applied in those countries.

\section{Diameter and Yield Strength of Reinforcement}

Steel reinforcing bars were investigated for bar diameters from $8 \mathrm{~mm}$ to $32 \mathrm{~mm}$. Data was taken from the result of tension tests of reinforcing steel used at the construction sites which are the same as those for the data of concrete compressive strength. The bars were produced by various manufacturers. The statistical parameters of bar diameters are summarized in Table 5.

Table 5

Statistical parameters of reinforcing steel diameter in Indonesia.

\begin{tabular}{|c|c|c|c|c|c|}
\hline No. & $\begin{array}{c}\text { Diameter } \\
\mathbf{m m}\end{array}$ & $\begin{array}{c}\text { Number } \\
\boldsymbol{n}\end{array}$ & $\begin{array}{c}\text { Mean } \\
\mathbf{m m}\end{array}$ & $\begin{array}{c}\text { Coef. of Variation } \\
\boldsymbol{V}\end{array}$ & $\begin{array}{c}\text { Bias factor } \\
\boldsymbol{\lambda}\end{array}$ \\
\hline 1. & 8 & 12 & 7.628 & 0.016 & 0.984 \\
\hline 2. & 10 & 17 & 9.839 & 0.011 & 0.981 \\
\hline 3. & 12 & 11 & 11.767 & 0.009 & 0.981 \\
\hline 4. & 13 & 52 & 12.989 & 0.008 & 0.983 \\
\hline 5. & 16 & 46 & 15.988 & 0.006 & 0.985 \\
\hline 6. & 19 & 33 & 18.994 & 0.004 & 0.991 \\
\hline 7. & 22 & 22 & 21.883 & 0.004 & 0.992 \\
\hline 8. & 25 & 73 & 24.986 & 0.009 & 0.984 \\
\hline 9. & 32 & 24 & 31,988 & 0.008 & 0.985 \\
\hline
\end{tabular}

The coefficients of variations of bar diameter were in the range of 0.004 to 0.016 . The coefficient of variation has no clear relation with the diameter. From Table 5, if the $V$ for diameter 25 and 32 -which less common to be used-are skipped, the $V$ values are tend to decrease with the increase in diameter, means the bigger diameter the more consistence the production. This information seem to be related to the quality control of the steel industry and 
fabricaton. The bias factor for all the investigated diameters was around 0.981 to 0.992 . It means that the diameter of reinforcing steel bars is slightly less than the nominal value.

The yield stresses of steel reinforcing bars from Indonesia of class BJTP $30\left(f_{y}=295 \mathrm{MPa}\right)$, and BJTS 40 ( $f y=390 \mathrm{MPa}$ ) were investigated and their statistical parameters are summarized in Table 6 . The coefficient of variation varies from 0.017 to 0.119 . Those values do not have certain relationship with the nominal grade or the diameter of reinforcing steel bar. The bias factors for strength of reinforcing steel bars vary from 1.213 to 1.381 . This information may lead to assumption that the manufacturer try to compensate the slightly reduction in diameter with the higher yield strength in order to reduce the weight of reinforcing steel.

\begin{tabular}{|c|c|c|c|c|c|c|}
\hline No. & $\begin{array}{l}\text { Grade } \\
\mathrm{MPa}\end{array}$ & $\begin{array}{l}\text { Diameter } \\
\text { mm }\end{array}$ & $\begin{array}{c}\text { Number } \\
n\end{array}$ & $\begin{array}{l}\text { Mean } \\
\mathrm{MPa}\end{array}$ & $\begin{array}{c}\text { Coef. of Variation } \\
\qquad V\end{array}$ & $\begin{array}{c}\text { Bias factor } \\
\lambda\end{array}$ \\
\hline 1. & \multirow{3}{*}{$\begin{array}{c}\text { BJTP } 30 \\
f y=295\end{array}$} & 8 & 12 & 376.93 & 0.108 & 1.278 \\
\hline 2. & & 10 & 6 & 407.25 & 0.017 & 1.381 \\
\hline 3. & & 12 & 11 & 374.29 & 0.119 & 1.269 \\
\hline 4. & \multirow{6}{*}{$\begin{array}{c}\text { BJTS } 40 \\
f y=390\end{array}$} & 13 & 38 & 493.95 & 0.048 & 1.266 \\
\hline 5. & & 16 & 37 & 493.23 & 0.083 & 1.265 \\
\hline 6. & & 19 & 33 & 496.47 & 0.063 & 1.273 \\
\hline 7. & & 22 & 22 & 473.02 & 0.046 & 1.213 \\
\hline 8. & & 25 & 73 & 512.05 & 0.107 & 1.313 \\
\hline 9. & & 32 & 24 & 477.67 & 0.065 & 1.225 \\
\hline
\end{tabular}

Table 6

Statistical parameters of fy of reinforcing steel in Indonesia.
Information on statistical parameter of reinforcing steel also found for the case of USA [2] as shown in Table 7. The highest value of $V$ is 0.065 and the lowest is 0.035 , while for value of $\lambda$ the range is between 1.200 and 1.125. Both coefficient of variation, $V$, and bias factor, $\lambda$, seem not having any correlation with the bar sizes.

\begin{tabular}{|c|c|c|c|c|c|}
\hline No. & $\begin{array}{c}\text { Diameter } \\
\mathbf{m m}\end{array}$ & $\begin{array}{c}\text { Number } \\
\boldsymbol{n}\end{array}$ & $\begin{array}{c}\text { Mean } \\
\mathbf{M P a}\end{array}$ & $\begin{array}{c}\text { Coef. of Variation } \\
\boldsymbol{V}\end{array}$ & $\begin{array}{c}\text { Bias factor } \\
\boldsymbol{\lambda}\end{array}$ \\
\hline 1. & 9.5 (No.3) & 72 & 496.1 & 0.040 & 1.200 \\
\hline 2. & $12.5($ No. 4$)$ & 79 & 473.3 & 0.065 & 1.145 \\
\hline 3. & $15.5($ No.5) & 116 & 465.1 & 0.040 & 1.125 \\
\hline 4. & $19($ No.6) & 38 & 476.1 & 0.050 & 1.150 \\
\hline 5. & $22($ No.7) & 29 & 481.6 & 0.050 & 1.165 \\
\hline 6. & $25($ No.8) & 36 & 473.7 & 0.050 & 1.145 \\
\hline 7. & 28 (No.9) & 28 & 475.7 & 0.050 & 1.150 \\
\hline 8. & 31 (No.10) & 5 & 470.2 & 0.040 & 1.140 \\
\hline 9. & 34.5 (No.11) & 13 & 473.7 & 0.035 & 1.145 \\
\hline
\end{tabular}

Statistical parameter for reinforcing steel from Indonesia shows the conditions that generally the measured diameter will slightly less than the nominal value. This finding is believed based on the well-known fact that reducing material volume can save material production cost. This fact is quite different with the condition in USA that the actual sizes tend to bigger than nominal value. In term of coefficient of variation, the consistency on diameter of reinforcing steel bars in Indonesia show better consistency than those in USA.

\section{Fabrication}

Fabrication factor of reinforced concrete structural members play important role on their performances. The preciseness of each detailed dimension and position of reinforcement affect such as the dead load, second moment of area, and moment arm. It also reflects the level of workmanship and affected by the appropriateness of equipment.
Table 7

Statistical parameters for reinforcing steel, Grade 420 Mpa (60 ksi) in USA [2]. 
Table 8 shows statistical parameter of concrete cover for beam and column. For the case of Indonesia, the concrete cover for beam seems to be less than nominal value. The coefficient of variation $V$ is 0.089 and the bias factor $\lambda$ is 0.913 . Even though the mean value is less than the nominal value, the value of $V$ indicates good consistency. The statistical parameters of concrete cover for beam from Japan show the value of $V$ higher than those from Indonesia. This might be related to various factors such as formwork, spacer and support system, and difficulties on project site, which are not covered in this research.

Table 8

Comparison of statistical parameters for concrete cover.

\begin{tabular}{|c|c|c|c|c|c|c|}
\hline Country & Member & $\begin{array}{c}\text { Number } \\
\boldsymbol{n}\end{array}$ & $\begin{array}{c}\text { Nominal } \\
\mathbf{m m}\end{array}$ & Mean & $\begin{array}{c}\text { Coef. of Variation } \\
\boldsymbol{V}\end{array}$ & $\begin{array}{c}\text { Bias factor } \\
\boldsymbol{\lambda}\end{array}$ \\
\hline \multirow{3}{*}{ Indonesia } & beam & 44 & 30 & 27.388 & 0.089 & 0.913 \\
\cline { 2 - 7 } & column & 40 & 40 & 49.000 & 0.140 & 1.225 \\
\hline \multirow{4}{*}{ Japan } & beam & 39 & 30 & 35.977 & 0.162 & 1.229 \\
\cline { 2 - 7 } & beam & 68 & 40 & 41.791 & 0.124 & 1.045 \\
\cline { 2 - 7 } & column & 382 & 40 & 56.906 & 0.177 & 1.427 \\
\cline { 2 - 7 } & column & 490 & 50 & 55.863 & 0.115 & 1.127 \\
\hline
\end{tabular}

Bias factors of concrete cover for column from Indonesia and Japan show the mean value bigger than the nominal value. The concrete cover of column is affected by difficulties arose from reinforcement arrangement, horizontal pressure from fresh concrete and total size of cross sectional spacer, and height of column. Data of concrete cover for column from Indonesia show the smaller coefficient of variation.

Table 9 shows comparison of the statistical parameter of measured member dimension from Indonesia, Japan, and USA. All sets of data have relatively small values of coefficient of variation $V$, which mean good consistency. The values of bias factor $\lambda$ are very close to 1 . The values of $V$ and $\lambda$ indicate that the actual member size is very close to the nominal size. Among the cases shown in Table 9, the coefficient of variation of beam size in Indonesia is higher than the other three cases of column and slab sizes. The reason for the difference cannot be found in this study.

\begin{tabular}{|c|c|c|c|c|c|c|}
\hline Country & Item & $\begin{array}{c}\text { Number } \\
n\end{array}$ & $\begin{array}{l}\text { Nominal } \\
\mathrm{mm}\end{array}$ & $\begin{array}{c}\text { Mean } \\
\text { mm }\end{array}$ & $\begin{array}{c}\text { Coef. of } \\
\text { Variation } \\
V\end{array}$ & $\begin{array}{c}\text { Bias } \\
\text { factor } \\
\lambda\end{array}$ \\
\hline \multirow{5}{*}{ Indonesia } & beam width, cast-in-place & 30 & 250 & 250.96 & 0.035 & 1.004 \\
\hline & beam height, cast-in-place & 36 & 500 & 496.14 & 0.026 & 0.992 \\
\hline & $\begin{array}{l}\text { column (square), cast-in- } \\
\text { place }\end{array}$ & 35 & 580 & 580.85 & 0.005 & 1.001 \\
\hline & $\begin{array}{l}\text { column (square), cast-in- } \\
\text { place }\end{array}$ & 40 & 700 & 700.52 & 0.005 & 1.001 \\
\hline & depth of slab & 37 & 120 & 123.25 & 0.094 & 1.027 \\
\hline \multirow{4}{*}{ Japan[1] } & beam width, cast-in-place & 39 & 700 & 709.68 & 0.007 & 1.014 \\
\hline & beam height, cast-in-place & 68 & 600 & 609.31 & 0.013 & 1.016 \\
\hline & $\begin{array}{l}\text { column (square), cast-in- } \\
\text { place }\end{array}$ & 382 & 700 & 701.18 & 0.009 & 1.002 \\
\hline & $\begin{array}{l}\text { column (square), cast-in- } \\
\text { place }\end{array}$ & 490 & 800 & 807.80 & 0.005 & 1.010 \\
\hline \multirow{7}{*}{ USA[2] } & width of beam, cast-in-place & - & - & - & 0.040 & 1.010 \\
\hline & $\begin{array}{l}\text { Effective depth } \\
\text { RC beam }\end{array}$ & - & - & - & 0.040 & 0.990 \\
\hline & $\begin{array}{l}\text { Effective depth of pre- } \\
\text { stressed concrete beam }\end{array}$ & - & - & - & 0.025 & 1.000 \\
\hline & $\begin{array}{l}\text { Effective depth of slab, } \\
\text { cast-in-place }\end{array}$ & - & - & - & 0.120 & 0.920 \\
\hline & $\begin{array}{l}\text { Effective depth of slab, } \\
\text { plant-cast }\end{array}$ & - & - & - & 0.060 & 1.000 \\
\hline & $\begin{array}{l}\text { Effective depth of slab, post- } \\
\text { tensioned }\end{array}$ & - & - & - & 0.080 & 0.960 \\
\hline & $\begin{array}{l}\text { Column width and } \\
\text { bread }\end{array}$ & - & - & - & 0.040 & 1.005 \\
\hline
\end{tabular}


As a summary, the statistical data shown in Table 8 and Table 9 indicate that the fabrication practice for dimensioning in Indonesia (2006 - 2008), Japan (1992 - 1994) and USA (around 2003) may be similar. It is a need to be stressed that if the comparison is made for similar period, the result could be different due to development on concrete technology in each place. The variation of concrete cover is relatively large, so that the mean value becomes a very conservative value. On the contrary, cross-sectional dimension is quite precise. This comparison of the statistical data on concrete cover and cross-sectional dimension implies that effective depth, which affects member strength and stiffness in both flexural and shear, may not be appropriately in safe side. The reduction of variation in concrete cover by providing appropriate spacer and formwork stiffness is suggested for fabrication practices in both Indonesia and Japan.

\section{Conclusions}

In order to have more reliable design, it is always important to understand the statistical characteristics in actual conditions of constructed structures and the effect of technology adopted on the statistical characteristics. The statistical parameters of material and fabrication of reinforced concrete members in Indonesia have been presented. The data from Indonesia were then partially compared with similar information from Japan and USA to see possible difference between the developing and developed countries.

Data from Indonesia, Japan, and USA for concrete compressive strength show the trend that the coefficient of variation $V$ decreases with the increasing concrete compressive strength. In addition, the data taken from particular ready-mixed concrete factories show smaller $V$ than those taken from several factories. Then, in term of reliability, if possible, it is suggested to use one ready-mixed concrete factory for each construction project.

Statistical characteristics of reinforcing steel bar diameter in Indonesia show the fact that the average bar diameter less than the nominal values, while the yield stress is always greater than the nominal value. This fact is similar to that in Japan. Both diameter and yield stress in Indonesia show the small $V$, indicating good consistency in steel bar fabrications. In term of yield stress, the condition in Indonesia is similar with those from USA, which the yield stress also showed the average higher than specified (see Table 7).

The statistical parameter for concrete cover of beams and columns show the small difference between Indonesia and Japan. The statistical parameter for dimension of beams and columns show the small difference between Indonesia, Japan, and the USA. The reduction in variation of concrete cover is suggested to improve the reliability of member strength and stiffness.

For the case of cast-in-place normal concrete with ordinary construction method in normal reinforced concrete building, statistical characteristics of material and fabrication in Indonesia are similar to those in Japan and USA. The data shown here were taken from middle upper class of construction company, indicating that for the lower class of construction company or lower level of construction scale, the statistics could be worse. The statistical characteristics presented in this paper would be useful for the development of reliability-based design in Indonesia. 


\section{ACKNOWLEDGEMENT}

The research reported in this article was conducted by the authors with the sponsorship of Japan International Cooperation Agency (JICA) under the project of ASEAN University Network (AUN) - Engineering Education Development Network (SEED-Net). The data in Indonesia were provided by Mr. Budi Suanda B.Eng., M.Eng and Mr. Gupit, B.Eng from construction companies while those in Japan were by Dr Watanabe Hiroshi of Public Work Research Institute, Dr Kawamura Chikara of Hokkaido Railway Co. Ltd. and Mr. Hisano Tokio of Sapporo TC Ready-mixed Concrete Co. Ltd. The authors are grateful to their kind cooperation for providing them the data. The contents of this article reflect the views of authors, who are responsible for the facts and accuracy of the data presented. 


\section{REFERENCES}

[1] Public Work Research Institute,"Investigation of on-site quality of ready-mixed concrete," Document of Public Work Research Institute, no.3409. Jan. 1996.

[2] A. S. Nowak and M. M. Szersen,"Calibration of design code for buildings (ACI 318): Part 1 - Statistical models for resistance," ACl Structural Journal, vol.100, no. 3, pp. 377-382, May-June 2003. 